\title{
Increment of Plasma Soluble CD14 Level in Carrageenan-Primed Endotoxin Shock Model Mice
}

\author{
Hiroyasu Hozumi, Yoshiyuki Adachi, Taisuke Murakami, Noriko N. Miura, and Naohito Ohno* \\ Laboratory for Immunopharmacology of Microbial Products, School of Pharmacy, Tokyo University of Pharmacy and Life \\ Science; 1432-1 Horinouchi, Hachioji, 192-0392 Tokyo, Japan. \\ Received December 10, 2005; accepted January 21, 2006; published online January 26, 2006
}

CD14 is membrane-associating or free soluble glycoprotein which recognizes lipopolysaccharide (LPS) and is assumed to be involved in the onset of endotoxin shock. There are some reports suggesting the relationship between increased expression of CD14 in infectious or inflammatory diseases. However, little has been reported concerning the soluble CD14 (sCD14) level, especially in mice. In this study, we measured the plasma level of sCD14, TNF- $\alpha$ and IL-6 in the iota-carrageenan (CAR)-primed endotoxin shock model in addition to the Dgalactosamine (D-galN)-primed endotoxin shock model mice. It was confirmed that all mice were dead within 12 $h$ after a higher dose of LPS-treatment in both animal models. The level of TNF- $\alpha$, IL-6 and sCD14 significantly increased in the CAR-primed endotoxin shock model mice. However, the D-galN-primed endotoxin shock model mice showed only a slight increment of TNF- $\alpha$ and IL-6 level, and sCD14 was below the detectable level. In the examination using several doses of LPS in CAR-primed model mice, IL-6 and sCD14 were increased dependent on the LPS dose, but TNF- $\alpha$ remained at an almost equal level at any dose of LPS in this study condition. In conclusion, the production of TNF- $\alpha$, IL-6 and sCD14 was significantly enhanced in the CAR-primed model mice, compared to the D-galN-primed model mice. Therefore, these data indicate the possibility that the sCD14 level did not increase consistently, even under a fatal condition in endotoxin shock. Also, CAR-primed endotoxin shock would be an important experimental model to examine the elevation mechanisms for sCD14 and IL-6 production.

Key words CD14; lipopolysaccharide; endotoxin shock model mice; tumor necrosis factor (TNF)- $\alpha$; interleukin (IL)-6

Lipopolysaccharide, the constituent of the outer membrane of Gram-negative bacteria is the major pathogen that strongly provokes macrophage activation, and is called "Endotoxin." When a large amount of LPS flows in the blood, monocytes and macrophages are activated and cytokines, for example, Tumor necrosis factor (TNF)- $\alpha$, interleukin (IL)-1, IL-6 and nitrogen monoxide (NO), are produced. As a result, the fever, the nettle rash, and the endotoxin shock are caused. Endotoxin shock is still a serious disease, and the mortality is also high. For instance, about 210000 patients a year are die due to endotoxin shock in the United States. ${ }^{1)}$ However, in recent years, the molecules related to LPS recognition have been detected and the mechanism of endotoxin shock has been gradually clarified. Toll-like receptor (TLR) $\left.4,{ }^{2-4)} \mathrm{MD}-2,5,6\right)$ Lipopolysaccharide Binding Protein (LBP) ${ }^{7}$ and CD14, ${ }^{8,9)}$ enumerated as molecules, recognize LPS. First, LBP recognizes to LPS and forms a complex. ${ }^{7)}$ In the next step, membrane CD14 (mCD14), expressed on the surface of monocytes and macrophages, or soluble CD14 (sCD14), expressed in the blood as the free form, recognizes the complex. The complex is transferred to TLR4/MD-2, and the activation of immunological cells is induced, for instance monocytes and macrophages. $\left.{ }^{9}, 10\right)$

CD14 is expressed on the surface of monocytes and neutrophils as a $55 \mathrm{kDa}$ GPI-anchored membrane protein (mCD14), and is also present in the serum as a soluble isoform. ${ }^{11)}$ There were some interesting reports about the relationship between soluble CD14 and its physiological role. One is that plasma sCD14 is increased and the expression level of mCD14 is decreased in the onset of sepsis. ${ }^{12)}$ And one of the other reports is that the responsibility to LPS was enhanced remarkably with CD14 existence compared with the condition in the absence of CD14. ${ }^{13)}$ On the other hand, an important role of sCD14 was reported, that it acts in promoting the recognition of LPS by epithelial cells, which do not express $\mathrm{mCD} 14$, in vitro. ${ }^{14)}$ These reports suggest that not only mCD14, but also sCD14, is an important receptor in LPS recognition.

There are some reports about increased level of sCD14, especially the sCD14 level in blood in the progress of the pathology, not only sepsis, ${ }^{15-17)}$ but also Kawasaki disease, ${ }^{18)}$ periodontitis $^{19)}$ and Alzheimer's disease. ${ }^{20,21)}$ Therefore, it is thought that CD14 is widely involved in inflammatory disease. To elucidate the relation between the kinetics of the CD14 level and the progress of the pathogenesis may contribute to finding the treatment method.

In this research, we compared the kinetics of the $\mathrm{SCD} 14$ level in different endotoxin shock models, the iota-carrageenan (CAR)-primed or D-galactosamine (D-galN)-primed model mice. Ogata et al..$^{22)}$ and our group ${ }^{23-26)}$ have been documented that increased TNF- $\alpha$ production might be related to the enhanced lethal toxicity in CAR-primed model mice. ${ }^{22)}$ Other report describes the mechanisms of the elevated sensitivity to LPS in CAR-primed model mice for the lethality. ${ }^{27,28)}$ In contrast, detailed analyses were performed in the D-galN-primed model mice, in which an increase of the number of apoptotic cells in the liver and of the responsiveness to TNF- $\alpha$ were observed. ${ }^{29-31)}$ In the present study, we examined the change of serum factors, including inflammatory cytokines and sCD14 in the CAR-primed endotoxin shock model mice. The characteristics of the CAR-primed model for studying sCD14 in the endotoxin shock model will be shown. 


\section{MATERIALS AND METHODS}

Animals Female ICR mice and C57BL/6 between 6 weeks of age were purchased from Japan SLC, Inc., Shizuoka and maintained under specific pathogen-free conditions. The breeding and handling of all animals in this experiment were approved by the Committee on Animal Experiments of the School of Pharmacy, Tokyo University of Pharmacy and Life Science.

Chemicals Phenol-extracted Escherichia coli (O111: B4) LPS and iota-carrageenan (CAR) were purchased from Sigma. Both LPS and CAR were dissolved in pyrogen-free physiological saline (Otsuka Pharmaceutical Co., Naruto, Japan). The CAR solution was autoclaved at $121^{\circ} \mathrm{C}$ for $15 \mathrm{~min}$ before use. D-Galactosamine hydrochloride, purchased from Wako Co., was dissolved in pyrogen-free physiological saline, and sterilized by using $0.2 \mu \mathrm{m}$ syringe filter before use.

Endotoxin Shock Model Mice CAR-primed endotoxin shock model mice was prepared as previous reports. ${ }^{23-26)}$ CAR ( $5 \mathrm{mg} / \mathrm{mouse}$ ) or saline was injected i.p., and mice were injected with LPS $(0.5,1,5,25,50,100 \mu \mathrm{g} /$ mouse $)$ or i.v. $24 \mathrm{~h}$ later. The strain of mice was female ICR, at 6 weeks of age.

D-galN-Primed Endotoxin Shock Model Mice: D-Galactosamine $(20 \mathrm{mg} / \mathrm{mouse})$ or saline injected and LPS (0.5 $\mu \mathrm{g} /$ mouse) or saline were injected immediately. The strain of mice was female C57BL/6, at 6weeks of age.

Lethality The cumulative percentages of lethality were determined by counting the number of dead mice for $48 \mathrm{~h}$ after LPS injection.

ELISA IL-6: A 96-well plate (Sumitomo Bakelite Co., Tokyo) was coated with rat anti-mouse IL-6 monoclonal antibody $(\mathrm{mAb})$ (Pharmingen, CA, U.S.A.) in bicarbonate buffer (pH 9.5) by incubation at $4{ }^{\circ} \mathrm{C}$ overnight. The plate was washed with phosphate-buffered saline (PBS) containing 0.05\% Tween 20 (Wako Pure Chemical Industries) (PBST) and blocked with $0.5 \%$ bovine serum albumin (Sigma) (BPBST) at $37^{\circ} \mathrm{C}$ for $40 \mathrm{~min}$. After another wash, the plate was incubated with recombinant mouse (rm) IL-6 (Pharmingen) or $50 \mathrm{ml}$ of sample at $37^{\circ} \mathrm{C}$ for $40 \mathrm{~min}$. It was then washed with PBST treated with biotinylated rat anti-IL-6 $\mathrm{mAb}$ (Pharmingen) at $37^{\circ} \mathrm{C}$ for $40 \mathrm{~min}$, before being treated with peroxidase-conjugated streptavidine (Pharmingen) at $37^{\circ} \mathrm{C}$ for $40 \mathrm{~min}$ and developed with a TMB substrate system (KPL Inc., MD, U.S.A.). Color development was stopped with $1 \mathrm{~N}$ phosphoric acid and the optical density was measured at $450 \mathrm{~nm}$.

TNF- $\alpha$ : A 96-well Nunc plate was coated with rat antimouse TNF- $\alpha$ mAb (Pharmingen) in phosphate buffer ( $\mathrm{pH}$ 6) by incubation at $4{ }^{\circ} \mathrm{C}$ overnight. The plate was washed with PBST and blocked with BPBST at room temperature (RT) for $2 \mathrm{~h}$. After further washing, the plate was incubated with rm-TNF- $\alpha$ (Pharmingen) or $50 \mathrm{ml}$ of sample at RT for $3 \mathrm{~h}$. It was then washed with PBST and treated with biotinylated rat anti-TNF- $\alpha$ mAb (Pharmingen) at RT for $1 \mathrm{~h}$. After another wash, the plate was treated with peroxidase-conjugated streptavidine (Pharmingen) at RT for $30 \mathrm{~min}$ and developed with a TMB substrate system (KPL Inc.). Color development was stopped with $1 \mathrm{~N}$ phosphoric acid and the optical density was measured at $450 \mathrm{~nm}$.
Preparation of sCD14 The plasmid expression vector, containing cDNA coding for amino acids from 1 to 320 of mouse CD14 was transfected into 293-EBNA cells. Recombinant mouse CD14 in the culture supernatant was purified by Ni-nitrilotriacetic acid agarose (Qiagen, Basel, Switzerland) chromatography using elution buffer with imidazole (250 mm).

Anti-mouse CD14 Polyclonal Antibody The CD14 fragment was obtained from the lysate of $E$. coli M15, which was transformed with a plasmid containing cDNA coding amino acids from 161 to 320 of mouse CD14. The purified CD14 fragment was injected subcutaneously into a rabbit. After that, anti-mouse CD14 antibody was purified from the rabbit serum by protein A-conjugated agarose. The antibody was biotinylated with Biotin- $\left(\mathrm{AC}_{5}\right)_{2}-\mathrm{OSu}$ (DOJINDO, Japan).

Western Blotting Western blot analysis was performed for the detection of sCD14. Mouse plasma was sampled from CAR-primed or non-primed mice, and D-galN-primed or noprimed mice before and after LPS or saline injection. The samples were mixed with a sample buffer containing $10 \% 2$ mercapto ethanol and heated in boiling water for $5 \mathrm{~min}$. This sample was analyzed using 10\% gel by SDS-PAGE. Biotinlabeled anti-CD14 rabbit polyclonal antibody diluted in blocking buffer was used for staining the blots, and the bound antibody was detected using anti-biotin, HRP-linked antibody (Cell Signaling TECHNOLOGY).

\section{RESULTS}

The Mouse Lethality of Endotoxin Shock Model System Using Different Priming Agents We have examined the LPS doses required for a similar lethal toxicity in both endotoxin shock models using CAR or D-galN as priming agents. In the preliminary studies to determine the adequate LPS doses, CAR-primed mice receiving with less than $10 \mu \mathrm{g} /$ mouse of LPS showed no lethal toxicity (data not shown). In contrast, all mice were dead by injecting with $100 \mu \mathrm{g} /$ mouse of LPS in CAR-primed mice as well as DgalN-primed model mice using $0.5 \mu \mathrm{g} /$ mouse of LPS injection. Therefore, the dose of LPS was determined as $100 \mu \mathrm{g} /$ mouse in CAR-primed model, and $0.5 \mu \mathrm{g} /$ mouse in D-galN-primed model in the following studies (Fig. 1). In the CAR-primed and LPS injected group, the mice began to die $4 \mathrm{~h}$ after LPS injection, and all mice died at $12 \mathrm{~h}$ after LPS injection. On the other hand, in the other groups of CAR alone or LPS alone injection, no dying mice were observed. In the D-galN and LPS injected group, the mice began to die $4 \mathrm{~h}$ after LPS injection, and all mice had died after $6 \mathrm{~h}$ had passed. On the other hand, in the other groups, injected with D-galN alone or LPS alone, no dying mice were observed.

In the conditions of this study, the lethality of both endotoxin shock model mice indicated a similar result. We observed that the lethal toxicity of LPS was enhanced to a fatal level in both endotoxin shock model mice.

Production of Inflammatory Cytokines Increased Remarkably in CAR-Primed Endotoxin Shock Model Mice Compared to D-galN-Primed Mice It was reported that the TNF- $\alpha$ production is remarkably increased in CARprimed endotoxin shock model mice. ${ }^{22,23,27,32)}$ In contrast, DgalN-primed endotoxin shock model mice showed a low 

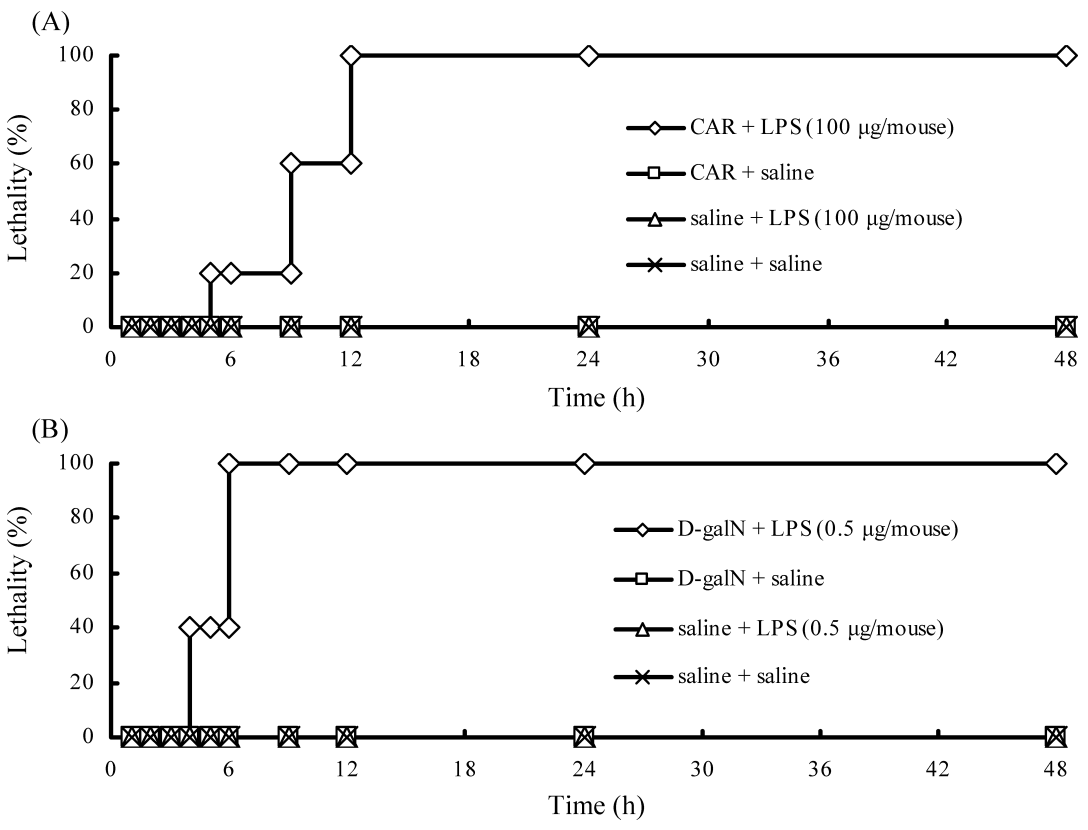

Fig. 1. Lethality of Endotoxin Shock Model Mice

(A) Cumulative mortality after injection of LPS or saline in CAR-primed and unprimed mice. CAR $(5 \mathrm{mg} / \mathrm{mouse})$ was injected i.p. $24 \mathrm{~h}$ prior to LPS or saline i.v. injection. Deaths were recorded for $2 \mathrm{~d}(n=10)$. (B) Cumulative mortality after injection of LPS or saline in D-galN-primed and unprimed mice. D-galN (20 mg/mouse) was injected i.p. $24 \mathrm{~h}$ prior to LPS or saline i.v. injection. Deaths were recorded for $2 \mathrm{~d}(n=5)$.

(A)

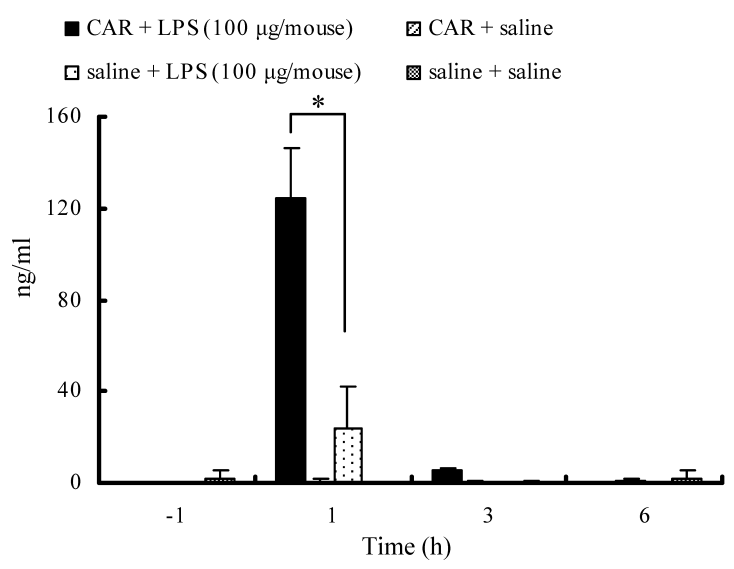

(B)

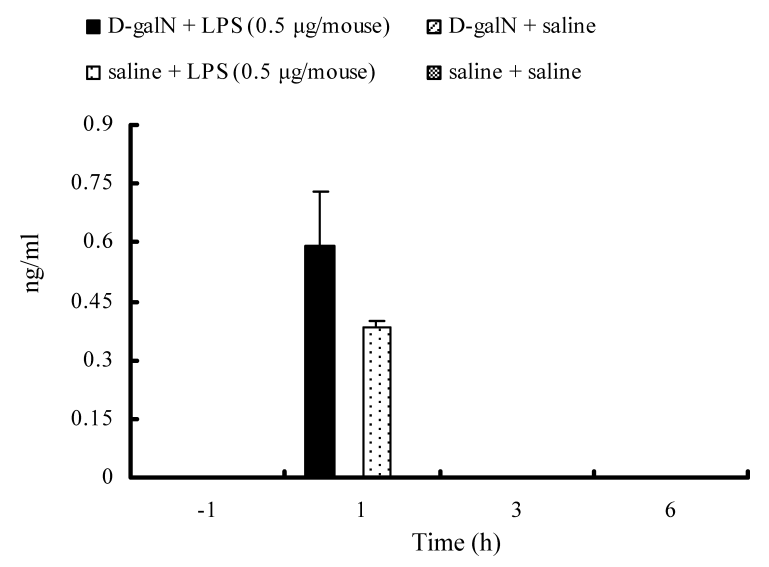

Fig. 2. TNF- $\alpha$ Level in Plasma of Endotoxin Shock Model Mice

(A) Mice were primed by i.p. administration of CAR ( $5 \mathrm{mg} / \mathrm{mouse})$ or saline. $24 \mathrm{~h}$ later, LPS (100 $\mu \mathrm{g} /$ mouse) or saline were administered i.v. Samples were prepared from CARprimed or unprimed and LPS- or saline-triggered ICR mice $(n=3)$. (B) Mice were primed by i.p. administration of D-galN (20 mg/mouse) or saline. At the same time, LPS $(0.5 \mu \mathrm{g} /$ mouse $)$ or saline were injected i.v. Samples were prepared from D-galN- or saline-administered and LPS- or saline-injected C57BL/6 mice $(n=3)$. $* p<0.05$.

level of TNF- $\alpha .^{30)}$ Therefore, we monitored the pro-inflammatory cytokines, including TNF- $\alpha$ and IL- 6 in both endotoxin shock model mice.

The TNF- $\alpha$ level was remarkably increased in the CARprimed endotoxin shock model mice compared to the D-galN primed group (Fig. 2). In addition, the IL-6 level was also remarkably increased in the CAR-primed endotoxin shock model mice. However, the IL-6 level in D-galN-primed endotoxin shock model mice is almost equal compared with those injected with LPS alone (Fig. 3).

These results suggest that the level of TNF- $\alpha$ and IL- 6 , at $1 \mathrm{~h}$ and $3 \mathrm{~h}$ after LPS injection respectively, in the CARprimed endotoxin shock model mice is different from DgalN-primed mice.

Soluble CD14 Increased in CAR-Primed Endotoxin
Shock Model Mice Compared to D-galN-Primed Mice In the present experiment condition, the mortality was analogous between the CAR-primed and the D-galN-primed model. However, the cytokines level at the monitoring time was not similar in these models. We examined the level of sCD14 in both endotoxin shock model mice using Western blotting analysis (Fig. 4).

In CAR-primed endotoxin shock model mice, the sCD14 level increased from $3 \mathrm{~h}$ after LPS injection, and the sCD14 level increased remarkably $6 \mathrm{~h}$ after LPS injection. The mice group that received $100 \mu \mathrm{g}$ of LPS alone showed an increased sCD14 level at $6 \mathrm{~h}$ after LPS injection, but the level was significantly lower than the treatment group with the combination of CAR-priming and LPS-triggering. Therefore, this result suggests that the enlargement of the sCD14 level 
(A)

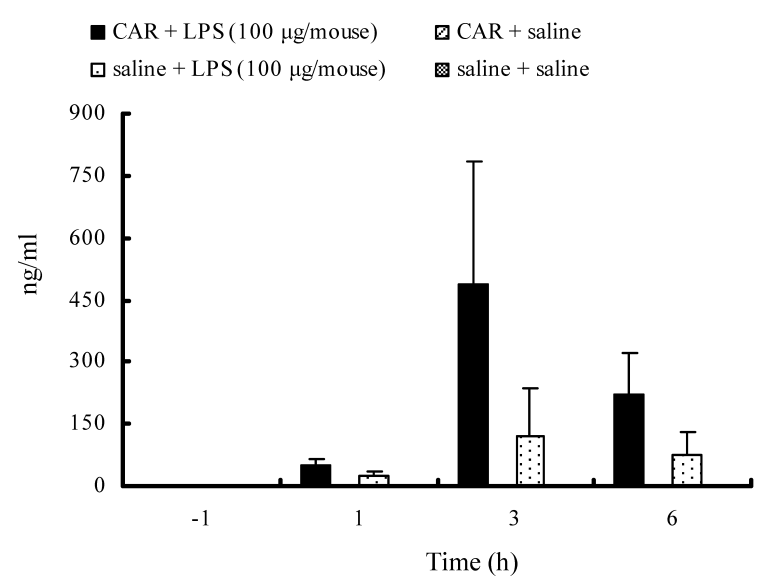

(B)
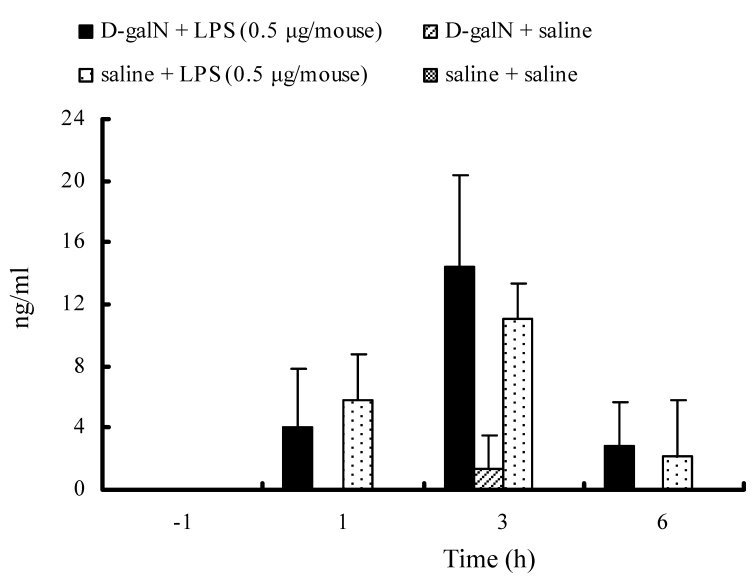

Fig. 3. IL-6 Level in Plasma of Endotoxin Shock Model Mice

(A) Mice were primed by i.p. administration of CAR ( $5 \mathrm{mg} / \mathrm{mouse})$ or saline. $24 \mathrm{~h}$ later, LPS ( $100 \mu \mathrm{g} / \mathrm{mouse})$ or saline were administered i.v. Samples were prepared from CARprimed or unprimed and LPS- or saline-triggered ICR mice $(n=3)$. (B) Mice were primed by i.p. administration of D-galN (20 mg/mouse) or saline. At the same time, LPS $(0.5 \mu \mathrm{g} /$ mouse $)$ or saline were injected i.v. Samples were prepared from D-galN- or saline-administered and LPS- or saline-injected C57BL/6 mice $(n=3)$.

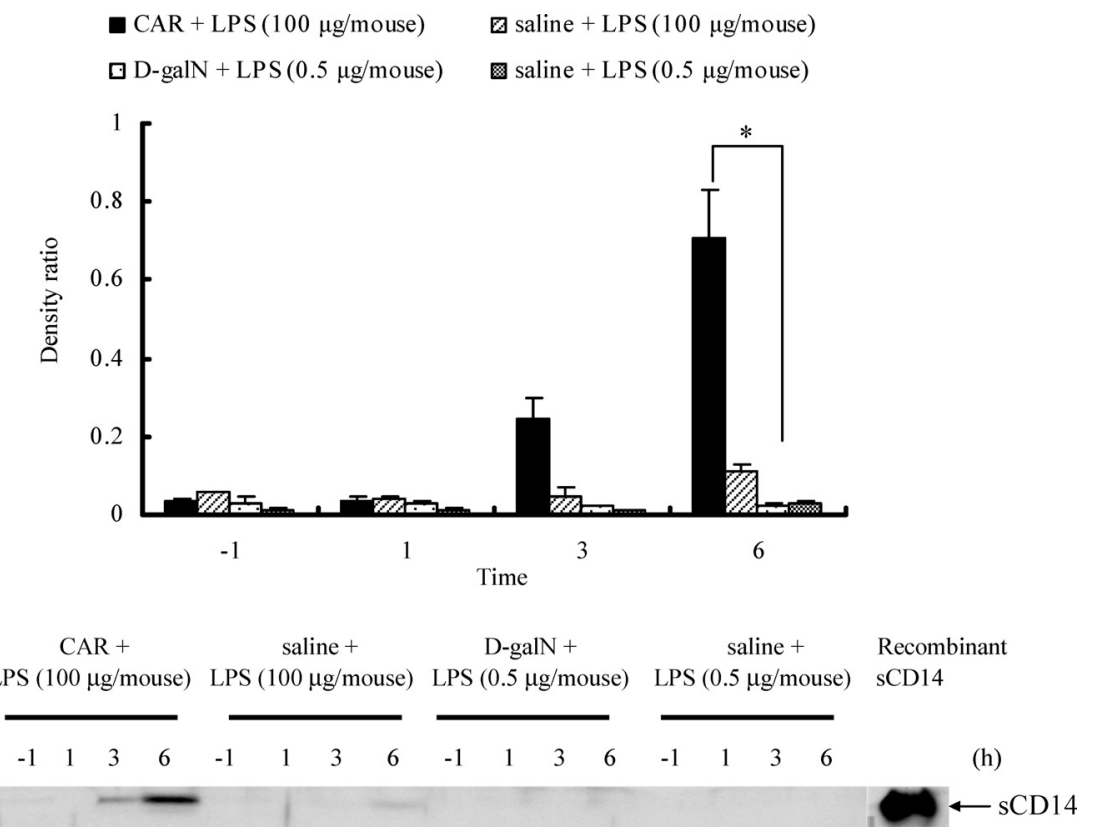

Fig. 4. sCD14 Level in Plasma of Endotoxin Shock Model Mice

Plasma were taken from mice administered with LPS at indicated time. The each plasma was diluted 20-fold with saline and subjected for SDS-PAGE and Western blotting. The sCD14 on the membrane was detected by probing with anti-mouse CD14 polyclonal antibody. Density ratio was calculated from recombinant sCD14's luminescence strength $(n=3) . * p<0.05$.

was strongly induced by the LPS stimulation under the CARprimed condition.

On the other hand, we did not detect any increase of the sCD14 level in D-galN-primed and LPS injected mice, and LPS injected mice. In addition, we examined whether the difference of the sCD14 level of these models was resulted from the strain difference of mice or the dose difference of LPS. The increment of the sCD14 level was observed in the plasma of CAR-primed and LPS-triggering, even in C57BL/6 mice (data not shown). Therefore, the increase of sCD14 is significantly dependent on the priming agents.

The LPS Dose Does Not Correlate to the Production of TNF- $\alpha$ in the Plasma, But Rather to IL-6 in the CARPrimed Endotoxin Shock Model Mice The sCD14 level after LPS-injection in the CAR-primed mice was different from that of the D-galN-primed endotoxin shock model mice. It was not clearly reported that there was a quantitative relationship between the dose of LPS and sCD14 in experimental shock models. Therefore, we next examined the dose dependency of LPS on the cytokine level in the plasma in CAR-primed endotoxin shock model mice. Then, we examined how the lethality, the TNF- $\alpha$, IL- 6 and the sCD14 level are changed under the condition, with different doses of LPS ranging from 0.5 to $50 \mu \mathrm{g} / \mathrm{mouse}$. The injection of LPS at more than $25 \mu \mathrm{g} /$ mouse, but not below $5 \mu \mathrm{g} /$ mouse, showed lethal toxicity (Fig. 5). All doses of LPS tested in this study induced TNF- $\alpha$ production with a peak at $1 \mathrm{~h}$ after LPStreatment. The concentration of TNF- $\alpha$ that appeared in the 


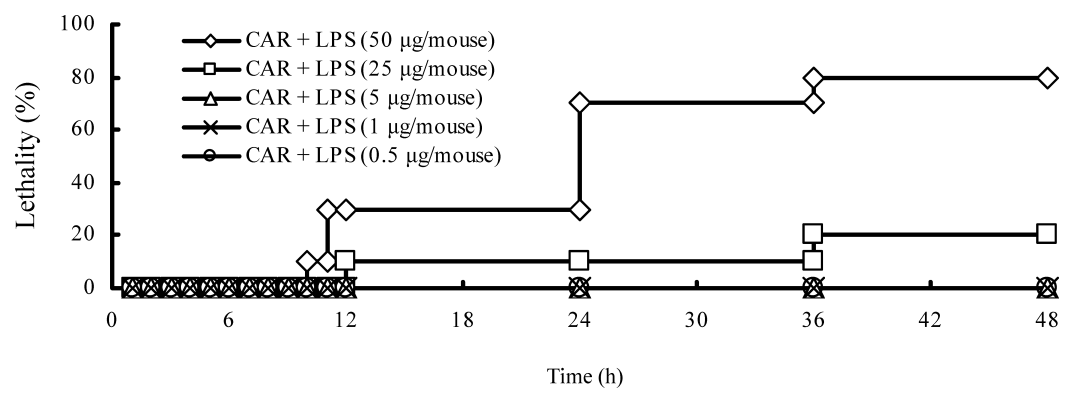

Fig. 5. Lethality of CAR-Primed Endotoxin Shock Model Mice in Various Dose of LPS

Cumulative mortality after injection of LPS in CAR treated mice. CAR $(5 \mathrm{mg} /$ mouse $)$ was injected i.p. $24 \mathrm{~h}$ prior to LPS i.v. injection. Deaths were recorded for $2 \mathrm{~d}(n=5)$.

(A)

- CAR $+\operatorname{LPS}(0.5 \mu \mathrm{g} /$ mouse $)$ $\square$ CAR + LPS $(5 \mu \mathrm{g} / \mathrm{mouse})$ $\square$ CAR + LPS $(50 \mu \mathrm{g} / \mathrm{mouse})$

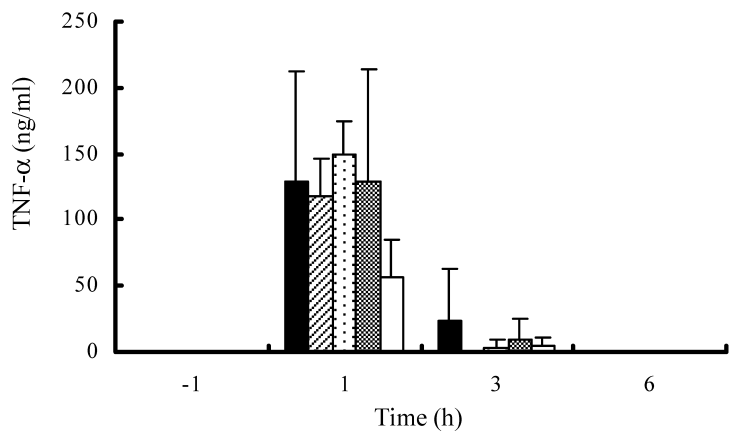

च CAR + LPS $(1 \mu \mathrm{g} /$ mouse $)$ 圆 CAR + LPS $(25 \mu \mathrm{g} / \mathrm{mouse})$
(B)

- $\operatorname{CAR}+\operatorname{LPS}(0.5 \mu \mathrm{g} / \mathrm{mouse})$ $\square \mathrm{CAR}+\operatorname{LPS}(5 \mu \mathrm{g} / \mathrm{mouse})$ च $\operatorname{CAR}+\operatorname{LPS}(1 \mu \mathrm{g} /$ mouse $)$ $\square$ CAR + LPS (50 $\mu \mathrm{g} / \mathrm{mouse})$ 圆 CAR + LPS $(25 \mu \mathrm{g} / \mathrm{mouse})$

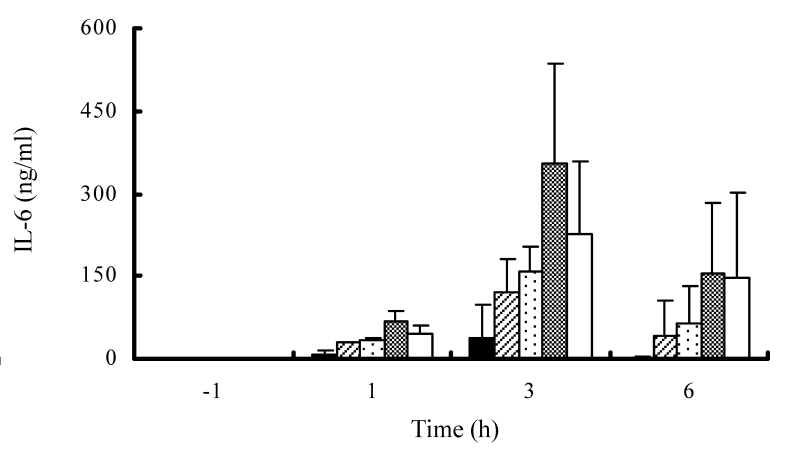

Fig. 6. Cytokine Production in Endotoxin Shock Model Mice in Various Dose of LPS

Mice were primed by i.p. administration of CAR ( $5 \mathrm{mg} /$ mouse). $24 \mathrm{~h}$ later, LPS $(0.5,1,5,25 \mathrm{or} 50 \mu \mathrm{g} / \mathrm{mouse})$ were administered i.v. Samples were prepared from CAR-primed and LPS-triggered ICR mice $(n=3)$. TNF- $\alpha(\mathrm{A})$ and IL- 6 (B) in the plasma were measured by ELISA.

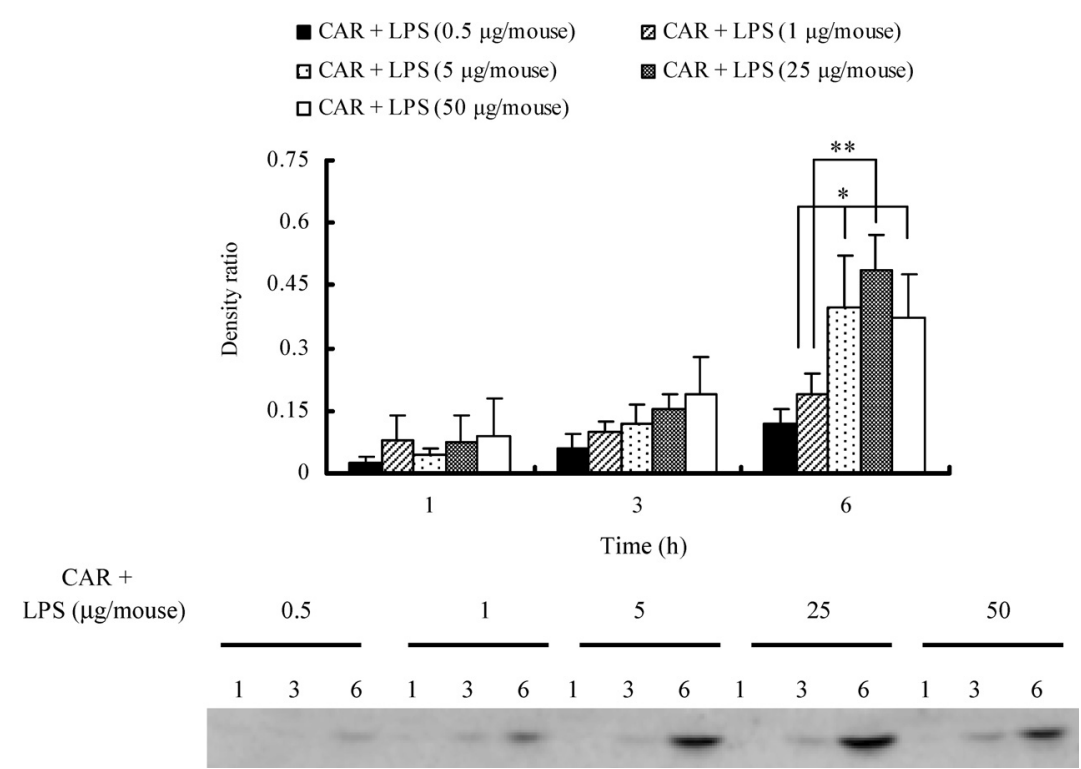

Fig. 7. sCD14 Level in Endotoxin Shock Model Mice in Various Dose of LPS

Plasma were taken from mice administered with LPS at indicated time. Soluble CD14 in plasma was detected as described in Fig. 4. Density ratio was calculated from recombinant sCD14's luminescence strength $(n=3) . * p<0.05, * * p<0.01$.

mouse plasma did not depend on the LPS dose (Fig. 6A). In contrast to the TNF- $\alpha$, the level of IL-6, which is increased at $3 \mathrm{~h}$ after LPS-injection, was dependent on the dose of LPS (Fig. 6B). These data indicated that the TNF- $\alpha$ production increased remarkably in a lower dose of LPS, which does not affect the lethality, though the production level of IL-6 de- pended on the dose of LPS.

Soluble CD14 Level in the Plasma Depends on the Dose of LPS in the CAR-Primed Mice The sCD14 level, as well as the mortality and the TNF- $\alpha$ and IL-6 level, was also examined using Western blotting (Fig. 7). The group that received $50 \mu \mathrm{g} /$ mouse of LPS with high mortality also showed 
a remarkable increase of the sCD14 level after $6 \mathrm{~h}$ LPS injection. In the other group, doses of LPS of 25 and $5 \mu \mathrm{g}$ /mouse produced a remarkable increase of the sCD14 level at $6 \mathrm{~h}$ after LPS injection. The increase of sCD14 level is detected with a peak at $6 \mathrm{~h}$ after LPS injection. We also observed an increase of the sCD14 level $6 \mathrm{~h}$ after lower dose of LPS was injected in the group to which a fatal toxicity did not appear. The time course of the sCD14 level was similar in all groups; namely, it peaked at $6 \mathrm{~h}$ after LPS injection, with a dose dependency of LPS. These data indicate that CAR-priming effectively induced TNF- $\alpha$, IL- 6 and SCD14 production in the stimulation with LPS.

\section{DISCUSSION}

In this study, we revealed the three following findings. First, the plasma level of TNF- $\alpha$, IL- 6 and sCD14 were remarkably increased in CAR-primed endotoxin shock model mice compared to D-galN-primed endotoxin shock model mice. Second, the increased plasma level of TNF- $\alpha$ was independent of the dose of LPS tested in this study, and did not correlate with the sCD14 level in the CAR-primed mice. The third finding is that plasma level of IL-6 and sCD14 depends on dose of LPS in the CAR-primed model mice.

Little is known about the mechanism that increases the lethality and plasma level of sCD14 in CAR-primed endotoxin shock model mice. Ogata et al. reported that the production of TNF- $\alpha$ was increased in CAR-primed endotoxin shock model mice, and this would be one of the reasons for the high mortality in this model. ${ }^{22,27,32)}$ However, a similar level TNF- $\alpha$ production was observed in either condition, fatal or non fatal, in our examination. Therefore, it is suggested that TNF- $\alpha$ synthesis was already saturated, even with sublethal dose of LPS tested. The enhanced TNF- $\alpha$ production does not account for the high lethality of CAR-primed model, although it is one of the important factor for endotoxin shock. ${ }^{27)}$

In contrast, the plasma level of IL- 6 and the sCD14 increased dependent on the dose of LPS. The IL-6 level at $3 \mathrm{~h}$ in CAR-primed mice showed a similar increment pattern in the plasma level of sCD14 at $6 \mathrm{~h}$, regarding the dependency on the LPS dose. Indeed, Sylvette et al. reported that IL-6 induced the enhancement of CD14 production. They also elucidated that CD14 mRNA in the liver of IL- $6+/+$ mice is enhanced, but not in IL-6-/- mice. Futhermore, the addition of recombinant IL-6 and soluble IL-6R in HepG2 culture resulted in the enhancement of sCD14 and cell-associated CD14 expression. ${ }^{33)}$ Therefore, it might be possible that not TNF- $\alpha$, but IL- 6 takes part in the increase of the SCD14 level in CAR-primed endotoxin shock model mice.

Recent reports regarding the endotoxin shock model using bacterial products or bacterial infection revealed a significant increment of $\mathrm{sCD} 14$ in the mice plasma. Morita et al. reported that serum $\mathrm{sCD} 14$ was increased under infection with Salmonella typhimurium aroA. The sCD14 level peaked at 9 to $12 \mathrm{~h}$ after LPS-injection or the bacteria infection to mice. It was shown that in $S$. typhimurium-infected mice, the plasma LPS level reached a plateau within $3 \mathrm{~h}$, and the level was maintained at a high concentration. They hypothesized that the $\mathrm{sCD} 14$ produced participates to form a complex with LPS ${ }^{34,35)}$ However, in case of CAR-primed mice, the concen- tration of LPS in the plasma after injection is still unknown. Therefore, further investigations to determine the relationship between the sCD14 level and LPS concentration are required to deduce the death mechanisms of CAR-primed endotoxin shock mice.

It is unclear how the sCD14 level was increased in the peripheral blood of the CAR-primed model. The mechanism of sCD14 release in the peripheral blood has been generally reported to involve shedding from plasma membrane-type CD14 on monocytes or macrophages by protease and phosphatidylinositol-specific phospholipase C (PI-PLC), ${ }^{36}$ or production from hepatocytes directly. ${ }^{37)}$ The pathway for generating sCD14 in the blood is complicated. Proinflammatory cytokines were also over-produced in the peripheral blood in the CAR-primed model. Although the origin of $\mathrm{sCD} 14$ in the circulation is uncertain, the expression of CD14 in hepatocytes is upregulated by stimulation with IL-6 either in vitro or in vivo. ${ }^{33)}$ Therefore, the generation of sCD14 in the CAR-primed mice may be due to indirect stimulation through upregulated IL-6 after LPS stimulation.

Our Western blotting analyses showed no increase of the sCD14 level in D-galN-primed model mice, even though DgalN-primed mice indicated a high lethality. These data indicate the possibility that the lethal condition is not an indispensable for the increase of the sCD14 level in the distinct endotoxin shock model. Although the sCD14 level was not increased in D-galN-primed model mice, an amount of evidence demonstrated that combination with D-galN-priming and LPS-triggering induces severe liver failure, with the apoptosis of hepatocytes. ${ }^{30,31)}$ Marino et al. reported the lethal mechanism of D-galN-primed TNF- $\alpha-/-$ mice. In this report, TNF- $\alpha-/-$ mice did not die, even with $100 \mu \mathrm{g}$ LPS administration. ${ }^{38)}$ These data indicated that TNF- $\alpha$ played a critical role in D-galN-primed model mice. Therefore, the lethal effect of TNF- $\alpha$ in the D-galN-primed model mice may be significantly different from that in the CARprimed model mice. The function of the TNF receptor in DgalN-primed model mice was also reported. The knockout mice with defects in either TNF receptor 1 (p55) $-/-$ or TNF receptor 2 (p75) - /- were tested for the effect of the receptors on the lethality. ${ }^{39-41)}$ The TNF receptor 1 knockout mice survived from hypersensitivity to TNF- $\alpha{ }^{41)}$ These results supported that TNF- $\alpha$ and TNF receptor 1 (p55) play a crucial role in the fatal mechanism of D-galN-primed model mice. The reason why the sCD14 level in the D-galN-primed model mice was not increased despite the high lethality with significant TNF- $\alpha$ production remains unclear. The mechanism resulting in no change of the $\mathrm{sCD} 14$ level in D-galNprimed model mice is an important problem requiring elucidation.

In this study, we have shown that the sCD14 level differs between the CAR-primed model and the D-galN-primed model mice. The fatal mechanism of the CAR-primed model mice was also not clarified by comparing the changes of the parameters of the CAR-primed model and the D-galN-primed model mice. As shown in the two different endotoxin shock models using D-galN or CAR as priming agents, the change of the SCD14 level is not consistent with the lethal toxicity. Thus, these results suggest the hypothesis that the case with the high sCD14 level reflects a specific condition like the CAR-primed model mice. The characteristics of the CAR- 
primed model for the endotoxin shock study are a high inflammatory response, as shown in TNF- $\alpha$ and IL-6 production, and a higher level of sCD14. In addition to the drastic change of physiological aspects, the experimental schedule is simple and does not require a long interval between priming and triggering agents, in contrast with other endotoxin shock models using bacterial product-priming, such as Propionibacterium acnes and Mycobacterium products BCG, which need 7 to $12 \mathrm{~d}$ before LPS triggering. ${ }^{42,43)}$

In conclusion, we propose that the CAR-primed endotoxin model might be useful for detecting significant levels of sCD14, although the mechanism relating to the lethal toxicity, especially the difference in priming effects between CAR-and other priming agents requires clarification. It is expected that the CAR-model may contribute to the development of an effective treatment procedure to prevent severe septic shock.

Acknowledgments We are very grateful to Ms. Kotone Murayama and Mr. Yo Fujise for their technical assistance. This work was supported by a Grant for private universities provided by the "Ministry of Education, Culture, Sports, Science and Technology" and the "Japan Private School Promotion Foundation.'

\section{REFERENCES}

1) Riedemann N. C., Guo R. F., Ward P. A., J. Clin. Invest., 112, 460 467 (2003).

2) Poltorak A., He X., Smirnova I., Liu M. Y., Van Huffel C., Du X., Birdwell D., Alejos E., Silva M., Galanos C., Freudenberg M., Ricciardi-Castagnoli P., Layton B., Beutler B., Science, 282, 2085-2088 (1998).

3) Hoshino K., Takeuchi O., Kawai T., Sanjo H., Ogawa T., Takeda Y., Takeda K., Akira S., J. Immunol., 162, 3749-3752 (1999).

4) Shimazu R., Akashi S., Ogata H., Nagai Y., Fukudome K., Miyake K., Kimoto M., J. Exp. Med., 189, 1777-1782 (1999).

5) Nagai Y., Akashi S., Nagafuku M., Ogata M., Iwakura Y., Akira S., Kitamura T., Kosugi A., Kimoto M., Miyake K., Nat. Immunol., 3, $667-672$ (2002).

6) Muroi M., Ohnishi T., Tanamoto K., Infect. Immun., 70, 3546-3550 (2002).

7) Wright S. D., Ramos R. A., Tobias P. S., Ulevitch R. J., Mathison J. C., Science, 249, 1431-1433 (1990).

8) Lynn W. A., Liu Y., Golenbock D. T., Infect. Immun., 61, 4452-4461 (1993).

9) da Silva Correia J., Soldau K., Christen U., Tobias P. S., Ulevitch R. J., J. Biol. Chem., 276, 21129-21135 (2001).

10) Akashi S., Saitoh S., Wakabayashi Y., Kikuchi T., Takamura N., Nagai Y., Kusumoto Y., Fukase K., Kusumoto S., Adachi Y., Kosugi A., Miyake K., J. Exp. Med., 198, 1035-1042 (2003).

11) Ulevitch R. J., Tobias P. S., Annu. Rev. Immunol., 13, 437-457 (1995).

12) Landmann R., Muller B., Zimmerli W., Microbes Infect., 2, 295-304 (2000).

13) Haziot A., Ferrero E., Kontgen F., Hijiya N., Yamamoto S., Silver J., Stewart C. L., Goyert S. M., Immunity, 4, 407-414 (1996).

14) Pugin J., Schurer-Maly C. C., Leturcq D., Moriarty A., Ulevitch R. J. Tobias P. S., Proc. Natl. Acad. Sci. U.S.A., 90, 2744-2748 (1993).

15) Landmann R., Zimmerli W., Sansano S., Link S., Hahn A., Glauser M. P., Calandra T., J. Infect. Dis., 171, 639-644 (1995).

16) Burgmann H., Winkler S., Locker G. J., Presterl E., Laczika K.,
Staudinger T., Knapp S., Thalhammer F., Wenisch C., Zedwitz-Liebenstein K., Frass M., Graninger W., Clin. Immunol. Immunopathol., 80 , 307-310 (1996)

17) Yaegashi Y., Shirakawa K., Sato N., Suzuki Y., Kojika M., Imai S., Takahashi G., Miyata M., Furusako S., Endo S., J. Infect. Chemother. 11, 234-238 (2005).

18) Takeshita S., Nakatani K., Tsujimoto H., Kawamura Y., Kawase H., Sekine I., Clin. Exp. Immunol., 119, 376-381 (2000).

19) Hayashi J., Masaka T., Ishikawa I., Infect. Immun., 67, 417-420 (1999).

20) Fassbender K., Walter S., Kuhl S., Landmann R., Ishii K., Bertsch T., Stalder A. K., Muehlhauser F., Liu Y., Ulmer A. J., Rivest S. Lentschat A., Gulbins E., Jucker M., Staufenbiel M., Brechtel K., Walter J., Multhaup G., Penke B., Adachi Y., Hartmann T., Beyreuther K., FASEB J., 18, 203-205 (2004)

21) Combarros O., Infante J., Rodriguez E., Llorca J., Pena N., FernandezViadero C., Berciano J., Neurosci. Lett., 380, 193-196 (2005).

22) Ogata M., Matsui T., Kita T., Shigematsu A., Infect. Immun., 67, 3284-3289 (1999).

23) Takada K., Ohno N., Yadomae T., Infect. Immun., 62, 1171-1175 (1994).

24) Takada K., Ohno N., Yadomae T., FEMS Immunol. Med. Microbiol., 9, $255-263$ (1994).

25) Takada K., Ohno N., Yadomae T., Circ. Shock, 44, 169-174 (1994).

26) Takada K., Ohno N., Yadomae T., J. Endotoxin Res., 2, 255-262 (1995).

27) Ogata M., Yoshida S., Kamochi M., Shigematsu A., Mizuguchi Y., Infect. Immun., 59, 679-683 (1991).

28) Matsumoto T., Yoshida S., Shiga Y., Kikuchi M., Sata T., Shigematsu A., FEMS Immunol. Med. Microbiol., 17, 171-178 (1997).

29) Bahrami S., Redl H., Leichtfried G., Yu Y., Schlag G., Infect Immun., 62, 99-105 (1994).

30) Bahjat F. R., Dharnidharka V. R., Fukuzuka K., Morel L., Crawford J. M., Clare-Salzler M. J., Moldawer L. L., J. Immunol., 165, 65596567 (2000).

31) Tsutsui S., Hirasawa K., Takeda M., Itagaki S., Kawamura S., Maeda K., Mikami T., Doi K., J. Vet. Med. Sci., 59, 785-790 (1997).

32) Ogata M., Matsumoto T., Koga K., Takenaka I., Kamochi M., Sata T., Yoshida S., Shigematsu A., Infect. Immun., 61, 699-704 (1993).

33) Bas S., Gauthier B. R., Spenato U., Stingelin S., Gabay C., J. Immunol., 172, 4470-4479 (2004).

34) Morita H., Hasunuma R., Kawaguchi K., Adachi Y., Tanaka S., Kumazawa Y., Biol. Pharm. Bull., 27, 1840-1843 (2004).

35) Kawaguchi K., Kikuchi S., Hasunuma R., Maruyama H., Yoshikawa T., Kumazawa Y., Biol. Pharm. Bull., 27, 679-683 (2002).

36) Hanada K., Izawa K., Nishijima M., Akamatsu Y., J. Biol. Chem., 268, 13820 - 13823 (1993).

37) Pan Z., Zhou L., Hetherington C. J., Zhang D. E., J. Biol. Chem., 275, $36430-36435$ (2000).

38) Marino M. W., Dunn A., Grail D., Inglese M., Noguchi Y., Richards E., Jungbluth A., Wada H., Moore M., Williamson B., Basu S., Old L. J., Proc. Natl. Acad. Sci. U.S.A., 94, 8093-8098 (1997).

39) Rothe J., Lesslauer W., Lotscher H., Lang Y., Koebel P., Kontgen F., Althage A., Zinkernagel R., Steinmetz M., Bluethmann H., Nature (London), 364, 798 -802 (1993).

40) Erickson S. L., de Sauvage F. J., Kikly K., Carver-Moore K., PittsMeek S., Gillett N., Sheehan K. C., Schreiber R. D., Goeddel D. V., Moore M. W., Nature (London), 372, 72560-72563 (1994).

41) Nowak M., Gaines G. C., Rosenberg J., Minter R., Bahjat F. R., Rectenwald J., MacKay S. L., Edwards C. K., 3rd., Moldawer L. L., Am. J. Physiol. Regul. Integr. Comp. Physiol., 278, 1202-1209 (2000).

42) Schwamberger G., Hammerl P., Ferber E., Freudenberg M., Galanos C., J. Leukoc. Biol., 74, 1056-1063 (2003).

43) Furusako S., Takahashi T., Mori S., Takahashi Y., Tsuda T., Namba M., Mochizuki H., Acta Med. Okayama, 55, 105-115 (2001). 